\title{
ДО ПИТАННЯ ПРО ПСИХОЛОГІЧНІ ТА СОЦІАЛЬНІ АСПЕКТИ ДИСТАНЦІЙНОГО НАВЧАННЯ ЛІКАРІВ-ПЕДІАТРІВ НА ПІСЛЯДИПЛОМНОМУ ЕТАПІ
}

\author{
О. А. Рижов, Ю. В. Котлова, К. О. Іванова, Т. О. Левчук \\ Запорізький державний медичний університет
}

\begin{abstract}
В статті подано психологічні і соціальні аспекти дистанційного навчання (ДН) лікарів- педіатрів на післядипломному етапі. Дослідження проводилося шляхом анкетування. Зазначено, що основним мотивом навчання для більшості лікарів $є$ професійне зростання, а перспективним методом навчання $є$ ДН. Респонденти вказали позитивні сторони ДН: зручність (гнучкий графік, можливість підвищувати свою кваліфікацію без відриву від виробництва), економічність, постійне надходження нової сучасної інформації та можливість негайно нею скористатись.
\end{abstract}

Ключові слова: дистанційна освіта, післядипломна медична освіта.

\section{К ВОПРОСУ О ПСИХОЛОГИЧЕСКИХ И СОЦИАЛЬНЫХ АСПЕКТАХ ДИСТАНЦИОННОГО ОБУЧЕНИЯ ВРАЧЕЙ-ПЕДИАТРОВ НА ПОСЛЕДИПЛОМНОМ ЭТАПЕ}

\author{
А. А. Рыжов, Ю. В. Котлова, Е. А. Иванова, Т. О. Левчук \\ Запорожский государственный медицинский университет
}

\begin{abstract}
В статье представлены психологические и социальные аспекты дистанционного обучения (ДО) врачей- педиатров на постдипломном этапе. Исследование проводилось путем анкетирования. Отмечено, что главным мотивом обучения для большинства врачей является профессиональный рост, а перспективным методом обучения является ДО. Респонденты выделили положительные стороны дО: удобство (гибкий график, возможность повышать свою квалификацию без отрыва от производства), экономичность, постоянное поступление новой современной информации и возможность незамедлительно ею воспользоваться.
\end{abstract}

Ключевые слова: дистанционное образование, последипломное медицинское образование.

\section{TO THE PROBLEM OF PSYCHOLOGICAL AND SOCIAL ASPECTS OF DISTANCE LEARNING PEDIATRICIAN POSTGRADUATE ON STAGE}

\author{
O. A. Ryzhov, Yu. V. Kotlova, K. O. Ivanova, T. O. Levchuk \\ Zaporozhye State Medical University
}

\begin{abstract}
In the article the psychological and social aspects of the controlled from distance educating (DE) of doctors of pediatricians are presented on the postgraduate education. Research was conducted by a questionnaire. It is marked that by main reason to educating for most doctors there is a professional height, and is DE the perspective method of educating. Respondents distinguished positive parties DE: comfort (flexible chart, possibility to promote the qualification without tearing away from a production), economy, quickness of receipt of new modern information, also possibility immediately to use her.
\end{abstract}

Key words: distance education, postgraduate medical education.

Современное дистанционное образование (ДО) охватывает самые различные модели, методы и технологии обучения:

- кейс-технология - подразумевает предоставление определённого набора учебных материалов (учебники, методические рекомендации, тесты и т.д.) на СД- дисках, рассылку материалов по почте, получение при личной встрече;

- сетевая технология - размещение учебных материалов на веб- сервере (учебники, лекции, контрольные работы), проведение лекций, семинаров и клинических разборов в режиме

(C) О. А. Рижов, Ю. В. Котлова, К. О. Іванова, Т. О. Левчук 


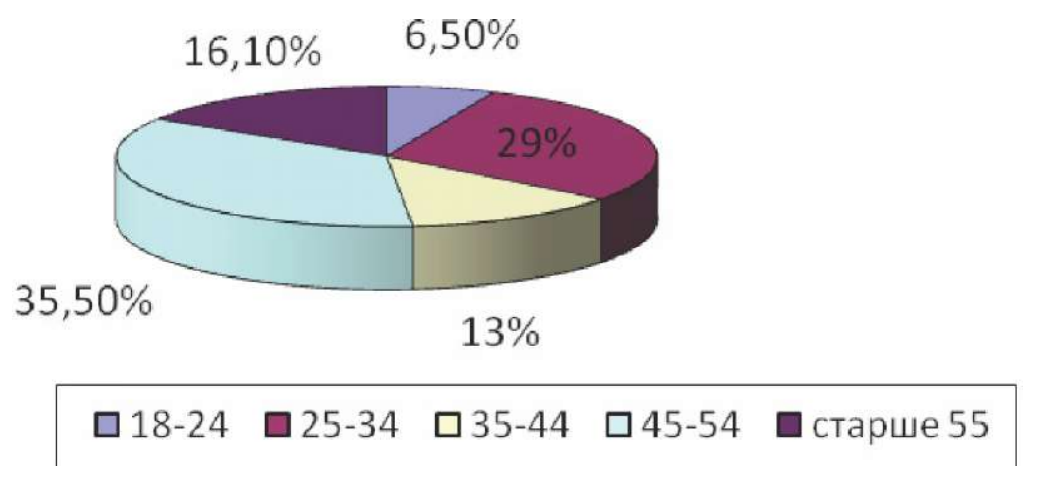

Рис. 1. Распределение опрошенных врачей по возрасту

реального времени. Связь с преподавателем осуществляется через интернет;

- телевизионная или телевизионно-спутниковая форма, отличается от предыдущей только тем, что связь с преподавателем осуществляется посредством спутниковой связи;

- смешанная форма предусматривает сочетание вышеуказанных форм с возможным включением периодов очного обучения, что необходимо для практической части обучения.

Дистанционному обучению (ДО) присущи такие преимущества, как мобильность, гибкость, доступность, технологичность. В существующих условиях оно является дешевым и общедоступным, открывая возможности общения на больших расстояниях. При этом необходимо учитывать наличие базовых навыков пользования компьютером и доступа к интернету с умением его использовать, наличие электронный почты для контакта с преподавателем и другими участниками обучения, а также индивидуально- психологические особенности обучающихся.

Цель работы: определить готовность и мотивации к обучению врачей на последипломном этапе, а также технических возможностей и экономической целесообразности дистанционного обучения врачей на циклах ТУ и ПАЦ по педиатрии в Запорожье и Запорожской области.
Материалы и методы исследования. Проведено анкетирование 126 практических врачей педиатров и врачей специальности «Общая практика семейная медицина» разных возрастных категорий, с достоверным преобладанием лиц женского пола (87,1 \% женщин, p<0,05) (рис.1).

Врачи были распределены по группам: 1-я группа (62 человека) была проанкетирована до организации очно- заочного обучения с помощью компьютерных технологий, 2-я группа (64 человека) - после проведения цикла обучения в режиме online. Анкета включала психологические вопросы: мотивация к обучению, отношение врача к разным формам обучения, восприятие информации при проведении цикла в режиме online; социальные вопросы: стоимость обучения для врача и для лечебного учреждения, замена врача на рабочем месте, отъезд на учебу, материальное положение семьи, наличие компьютера и умение его использовать.

Результаты и их обсуждение. В результате анализа анкет выявлено, что главным мотивом к обучению для $87,1 \%$ респондентов обеих групп был профессиональный рост, для 42,5 \% опрошенных карьерный рост, у 8,1 \% окончание срока действия сертификата, а для 11,3 \% - финансовая сторона (табл. 1).

При опросе респондентов 1- й группы с опытом только традиционного обучения отмечено, что по-

Таблича 1

Оценка мотивации врачей к обучению

\begin{tabular}{|l|c|}
\hline \multicolumn{1}{|c|}{ Причины } & Количество респондентов, \% \\
\hline Профессиональный рост & 87,1 \\
\hline Карьерный рост & 42,5 \\
\hline Длительный перерыв в работе из- за болезни или по другим причинам & 16,1 \\
\hline Окончание действия сертификата & 8,1 \\
\hline Финансовый мотив & 11,3 \\
\hline
\end{tabular}


Приоритетность ДО

\begin{tabular}{|l|c|}
\hline \multicolumn{1}{|c|}{ Причины } & Количество респондентов, \% \\
\hline качественное обучение доступное для всех & 38,2 \\
\hline обучение по месту жительства & 48,4 \\
\hline экономия временных и финансовых затрат & 45,0 \\
\hline $\begin{array}{l}\text { непосредственный контакт с известными отечественными и зарубежными } \\
\text { специалистами }\end{array}$ & 40,3 \\
\hline возможность получить материалы обучения в виде презентаций & 32,3 \\
\hline $\begin{array}{l}\text { возможность незамедлительно использовать новую информацию, полученную } \\
\text { на занятиях, в своей работе }\end{array}$ & 31,7 \\
\hline
\end{tabular}

чти $60 \%$ врачей не имели четкого представления о ДО. На вопрос «Как вы понимаете определение «Дистанционное образование» только 41,9 \% врачей ответили, что «ДО - это очно- заочная форма обучения с проведением лекций, семинаров и клинических разборов в режиме реального времени, наличием связи с преподавателем через интернет, которая также включает самостоятельное обучение с использованием учебных материалов на веб- сервере. 29 \% врачей считали, что ДО - это только заочная форма обучения без контакта с преподавателем. Такое же количество врачей ответило, что ДО - это очная форма обучения, включающая только проведение лекций дистанционно в режиме реального времени.

Это объясняет, почему на вопрос о предпочтительной для них форме обучения $40 \%$ респондентов 1- й группы выбрали очное обучение, аргументируя его преимуществами по сравнению с ДО. На их взгляд, наиболее важным недостатком дистанционного образования является ослабление человеческого контакта и снижение эффективности обучения из-за слабого влияния личности педагога (30 \%). 14,5 \% врачей считают, что при ДО информация предоставляется только на бумажных носителях. Почти для 20 \% врачей преградой к ДО является отсутствие личного компьютера и неумение его использовать.

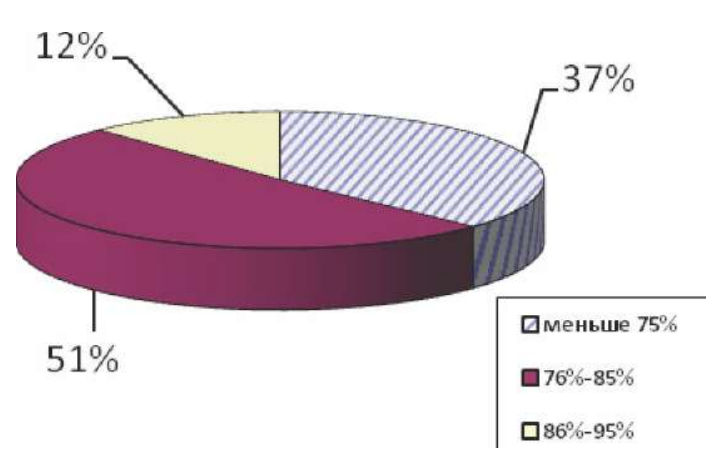

Рис. 2. Результаты тестирования до обучения
При обучении врачей 2-й группы на кафедре детских болезней ФПО ЗГМУ использовали смешанную форму ДО (очно- заочное обучение «blended education»). Из-за нехватки технических средств и отсутствия достаточных знаний информационных технологий группа слушателей формировалась в лечебном учреждении, по месту работы, в аудитории с одним компьютером и участием специалиста (инженер-технолог).

Основу обучения при данной форме ДО составлял курс лекций и вебинаров в режиме реального времени для группы врачей в удаленном классе, что позволяло дискутировать и задавать вопросы в прямом эфире. За счёт использования мультимедийных средств (презентации, фотографии, аудио- и видеоматериалы) обучение становится более активным, интересным, повышается усвоение и запоминание представленных материалов. Интерактивный контакт позволяет слушателям получить ответы на возникшие вопросы, ощутить харизму преподавателя. Важными элементами обучения являются семинары с участием главных специалистов области по наиболее актуальным проблемам. Еженедельно по пятницам проводились клинические разборы сложных для диагностики (с анализом диагностического поиска) пациентов и больных с редкими патологиями, находящихся

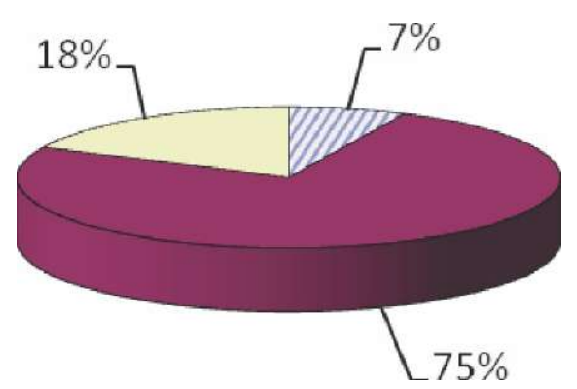

Рис. 3. Результаты тестирования после обучения 


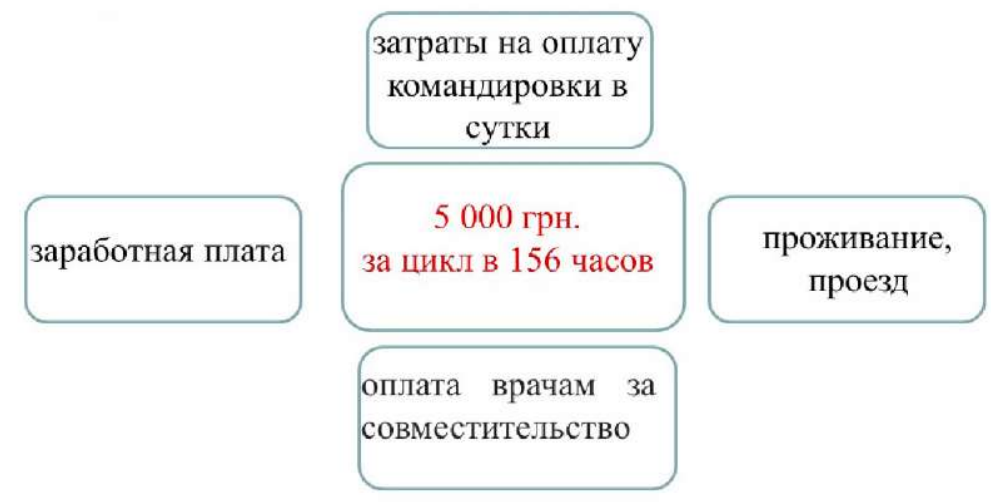

Экономия средств Веселовской ЦРБ на обучении 22 врачей очнодистанционно составила 238050 грн.

Рис. 4. Экономическая целесообразность, приблизительные затраты на обучение 1 врача (по состоянию на 2013)

на лечении в стационаре, что позволило расширить эрудицию и опыт слушателей. Самостоятельная работа включала изучение слушателями электронных учебных материалов с вопросами для самоконтроля в системе ДО мoodle.

Респонденты 2-й группы с опытом обучения дистанционно и имеющие полное представление о данной модели обучения, в 100 \% случаев предпочитают ДО в дальнейшей деятельности, отмечая при этом его преимущества (табл. 2).

Результаты тестирования слушателей ТУ и ПАЦ до и после окончания курса методом очно-заочного обучения показал, что ДО является эффективным методом обучения: 93 \% респондентов показали достаточный уровень по результатам тестирования (от 86 до 95 \% правильных ответов), что достоверно выше, чем при базовом тестировании (рис. 2, 3).

Важным преимуществом ДО является его экономичность. На примере Веселовской ЦРБ была рассчитана экономическая целесообразность ДО. Экономия средств Веселовской ЦРБ на очно-дистанционном обучении 22 врачей составила 238050 грн. (рис. 4). Расходы включали стоимость обучения на циклах ТУ и ПАЦ, затраты на оплату командировки, заработную плату, проживание, проезд, заработную плату врачасовместителя на время отсутствия основного работника.

Выводы. 1. Главным мотивом к обучению для 87,1 \% врачей является профессиональный рост, при этом ДО является перспективным и приемлемым видом обучения для 100 \% респондентов.

2. Удобство и экономичность, а также быстрота поступления новой современной информации, возможность незамедлительно её использовать, делает ДО незаменимым для повышения квалификации врачей-педиатров на последипломном этапе образования.

\section{Литература.}

1. Приказ Министерства образования и науки Украины от 25 апреля 2013 года № 466 «Об утверждении Положения о дистанционном обучении».

2. Агранович Н. В. Возможности и эффективность дистанционного обучения в медицине / Агранович Н. В., Ходжаян А. Б. // Фундаментальные исследования. - 2012. - № 3-3. - С. 545 - 547.

3. Ядровская М. В. Модели учебно- педагогической коммуникации в системе электронного обучения вуза / Ядровская М. В. // Образовательные технологии и общество. - 2013. - № 2, том 16. - С. 469- 486.

4. Безперервний медичний професійний розвиток - нові стратегії передавання знань / О. П. Мінцер, О. В. Голяновський, С. В. Денисенко // Мед. освіта: наук.- практ. журн. - 2012. - № 2. - С. 55 - 56.

5. Современная философия трансфера знаний в последипломном медицинском образовании / Ю. В. Вороненко, О. П. Минцер, Д. Д. Иванов // Новости медицины и фармации. - 2012. - № 20/22. - С. 7.

6. Организация преподавания вопросов оказания неотложной помощи детям в режиме дистанционного обучения / Л. Н. Боярская, Е. И. Подлианова, Ю. В. Котлова // Запорожский медицинский журнал - 2012. - № 6. - С. 118. 7. Технології дистанційного навчання лікарів- педіатрів / Л. М. Боярська, О. А. Рижов, Ю. В. Котлова // Актуал. питання фармац. та мед. науки та практики. - 2014. - № 1. - С. 87- 88.

8. Опыт преподавания заболеваний детского возраста с помощью компьютерных технологий на циклах тематического усовершенствования в ЗГМУ/ Л. Н. Боярская, Ю. В. Котлова, Е. И. Подлианова и др. // Запорожский медицинский журнал. - 2012. - № 6. - С. 86- 87. 